\title{
Using the Internet to extend training in team problem solving
}

\author{
LOUIS J. KRUGER \\ Northeasterm University, Boston, Massachusetts \\ STEVE COHEN \\ Tufts University, Medford, Massachusetts \\ DAVID MARCA \\ Marca and Associates, Marlboro, Massachusetts \\ and \\ LUCIA MATTHEWS \\ Northeastern University, Boston, Massachusetts
}

\begin{abstract}
A hybrid training approach, composed of both computer-mediated communication on the Internet and face-to-face meetings, was implemented. The goals were to examine whether such an approach (1) could be used to extend traditional, short-term training, and (2) would be perceived as useful by the trainees. A central element of the approach was the linchpin expert, a trainer who served as a communication bridge on the Internet between a team of trainers and a team of trainees. A coding system was developed to analyze the content of the Internet messages. Logistic regression analysis revealed that two types of content were related to the trainees' perceptions that the messages enhanced their expertise in team problem solving: (1) outcome feedback given to a trainee about a specific activity, and (2) the sharing of conceptual information. The trainees perceived face-to-face and computermediated communications with the linchpin expert as being important to their development of expertise.
\end{abstract}

Considerable organizational resources have been devoted to improving the expertise of professional workers (Moorhead \& Griffin, 1995). Indeed, workers in the 21st century will need to be much better trained than their 20thcentury counterparts (Johnston, 1988), and thus there will be a parallel need for creative ways of training and retraining workers. Recent research (e.g., Ericsson, Krampe, \& Tesch-Romer, 1993; Short \& Rinehart, 1993) indicates that systematically implemented learning activities can facilitate expertise, and therefore, that expertise could be considered a goal for training programs.

An important obstacle to reaching such a goal is the limited nature of typical training programs. Most training programs are relatively short, ranging from an afternoon to a few days, and occur in a group format. Thus, trainees often do not have the structure they need in order to practice and improve their skills over time. In addition, the training typically takes place outside of the work environment, which interferes with the trainees' ability to transfer what they have learned to their work (Collins, 1986). In contrast, the development of expertise requires

The authors would like to thank Charles Lawrence, Alvan Hyman, Durwood Marshall, and Julie Chapin for their assistance. Correspondence concerning this article may be sent to L. Kruger, Department of Counseling Psychology, Rehabilitation, and Special Education, 203 Lake Hall, Northeastern University, Boston, MA 02115 (e-mail: counsel@ neu.edu). a sustained and highly individualized training program composed of practice and feedback that is incorporated into a person's daily routine (Ericsson et al., 1993). However, long-term, face-to-face (FTF) training with extensive feedback is time consuming and costly.

Computer-mediated communication (CMC) is one possibly efficient way of extending traditional short-term training. Through $\mathrm{CMC}$, ongoing training could be provided to workers who wanted to further develop and use their expertise in the natural work environment. For instance, to promote the type of activities that have been found to be useful in enhancing expertise, a trainer could use electronic mail to provide the trainee with specific feedback about work-related activities (Ericsson et al., 1993) or to suggest how the trainee can use his/her mail account to compose and store self-reflections (Short \& Rinehart, 1993). As a result of these considerations, we have developed and investigated a hybrid approach, composed of group FTF training and CMC on the Internet, as a means of providing the sustained and individualized training needed to promote expertise in team problem solving.

Though previous research has compared CMC with FTF meetings as alternate approaches to accomplishing work tasks (e.g., Kraut, Galegher, Fish, \& Chalfonte, 1992; Siegel, Dubrovsky, Kiesler, \& McGuire, 1986), we combined these two approaches because in most work settings where CMC is used, it is used in conjunction with 
FTF meetings. We used a case study design and focused our data collection on one team of trainees because we wanted to understand what was useful about our overall training approach, as well as ascertain what was useful about the specific aspects of the computer-mediated training. In regard to the latter, we examined the relationship between the content of Internet messages and their perceived value in enhancing expertise. The examination of the trainees' perceptions might be useful for two reasons. First, people's perceptions of their training have been found to influence the extent to which they learn (Warr, 1995). Second, perceived utility can have a strong relationship to actual, later use (Davis, 1989). Given that a major goal of most training programs is the transfer of the learning to the workplace, the examination of such perceptions seems important.

In order to analyze the trainees' perceptions of the messages, we developed a coding system for the content of the messages. In particular, the coding system was used to assess the communication of different types of (1) outcome feedback (i.e., specific and global feedback to individuals, group feedback) and (2) information (i.e., conceptual, observation-based, personal). Outcome feedback provides the recipient with an evaluation of the results of an activity. Outcome feedback has been considered to directly affect learning (Bangert-Drowns, Kulik, Kulik, \& Morgan, 1991), as well as to facilitate the development of expertise (Ericsson et al., 1993). However, previous research has not addressed the potential value of computer-mediated feedback in the context of a training program. Information categories were included in the coding system because it has been argued that outcome feedback is most effective when it is linked with other types information (Butler \& Winne, 1995). By means of these content categories, we sought to begin to understand how people should compose Internet messages for the purpose of facilitating training.

The unit of analysis for coding was the entire electronic message. Though a considerable amount of research on CMC has focused on the level of the individual remark (e.g., Siegel et al., 1986), a whole message approach to data analysis is also justifiable. In particular, a message is the naturally occurring unit of electronic mail, and therefore it seems reasonable to probe people's perceptions of this naturally occurring unit.

In summary, we investigated two primary questions: (1) What types of CMC feedback and information would be related to trainees' perceptions that a message enhanced their expertise in team problem solving? (2) To what extent would trainees perceive that $\mathrm{CMC}$ enhanced their expertise in team problem solving? In addition, we assessed the trainees' perceptions of the relative effectiveness of the different aspects of FTF and computermediated training.

\section{METHOD}

\section{Participants}

The trainees were a team of three teachers, three principals, and a superintendent from the same suburban school system. Prerequi- sites for their participation included (1) convenient access to computer equipment and a telephone line for Internet access, (2) a commitment to meet FTF as a group at least twice a month, and (3) identification of a "real-world" problem that the team wanted to improve. Five of the 7 participants each read or composed at least $32.7 \%$ of the messages. However, 2 of the trainees, a principal and a teacher, read and/or composed only $8.3 \%$ and $7.1 \%$ of the Internet messages, respectively. Self-reported barriers to their greater participation were work pressures and an unreliable Internet connection. Because of these 2 individuals' infrequent use of the electronic mail part of the project, we focused our data analysis on the other 5 trainees (hereafter referred to as participants).

The mean age of the 5 participants was $45.40(S D=4.51)$. They had an average of 13.40 years of work experience $(S D=11.10)$ in their current school system. Four were women. Overall, the participants were relative novices in using electronic mail. Only 2 of the 5 had previous experience in using electronic mail, and neither of these had used electronic mail for more than 1 year. On the average, the 5 estimated that they spent $50.6 \%(S D=36.22 \%)$ of their work time in teams. Only 1 of the participants reported previous training in teamwork, and 2 claimed to have had previous training in problem solving.

\section{Implementation of Training}

The content of the training focused on team problem solving. Training in team problem solving had practical relevance for our group of trainees, who were public school professionals. Many of these individuals are now providing instructional and related services as members of teams. Moreover, educational change efforts often emphasize a team or collaborative approach to service delivery and instruction (see, e.g., Fullan, 1991; Stevens \& Slavin, 1995). We wanted to explore whether or not it was useful to employ FTF and computer-mediated training as a means of helping school professionals work interdependently toward identifying and intervening with a problem in their school system.

The initial FTF training occurred during 3 consecutive days. Each session was approximately 6 hours in duration. Topics addressed in these training sessions were: (1) using electronic mail, (2) team development, and (3) problem solving. The team training focused on assigning roles (e.g., leader) and making team decisions (e.g., using the nominal group technique). The problem-solving sessions provided an overview of the process and emphasized the initial steps (e.g., defining the problem). FTF follow-up sessions addressed subsequent steps in the problem-solving process through that of how to summarize the data that the participants had collected on their problem. In the present instance, the problem was a lack of community support for public education in their town.

Two important strategies guided our training. One strategy consisted in the use of a linchpin expert: one member of the trainers' group who gave all training subsequent to the initial FTF training. This trainer was the communication bridge between the other trainers and the trainees. The linchpin expert strategy helped us avoid the possibility of flooding the trainees with CMC from multiple trainers, which might have confused the trainees. We also believed that the linchpin expert was in the best position to judge what feedback or ideas the trainees' team needed because of his close working relationship with the team. Finally, assigning only one of the experts to work with the trainees is consistent with type of mentoring relationship that is needed for trainees to develop expertise (Ericsson et al., 1993). Therefore, all suggestions from the training group were first communicated to the linchpin expert, who then decided what would be communicated to the trainees.

A second important strategy of the training approach involved CMC. Internet accounts were established for all trainers and trainees on a university computer system, and all used the same electronic mail system. The system was text based and had rudimentary features, such as the storing of messages. Each trainee was able to send Internet messages to and receive these messages from three individuals: (1) the linchpin expert, (2) his/her team members, and (3) him- 
self/herself (i.e., a self-reflection sent to the person's own Internet account). Self-reflections were included as an electronic mail option because research has indicated they can lead to enhanced expertise (e.g., Short \& Rinehart, 1993). The Internet server was programmed so that all the trainers were able to read the electronic messages from the trainees, as well as those between the linchpin expert and the trainees. This afforded the trainers a verbatim, longitudinal perspective on the progress of the trainees. In addition, the trainers were able to electronically communicate among themselves.

\section{Measures}

All Internet messages from the training group and the trainees were automatically stored in one computer file. With a coding system developed for this study, each message was assigned one or more of eight content categories. Table 1 lists the content categories. The coding system and several of the content categories were derived in part from Cherniss's (1986) system for observing supervisory behavior. Four of the categories of his system, which were adapted for use in our system (i.e., specific feedback, global feedback, social support, and directing) were derived from assumptions about how supervisors can facilitate the effectiveness and professional development of their staff. Such notions of supervision seem consistent with our use of the linchpin expert as mentor. The content category of directing was redefined and renamed suggesting, in

\section{Table 1}

Definitions of Content Categories and Percent Occurrence in Messages

\begin{tabular}{cc}
\hline Content Category & $\begin{array}{c}\text { Percent } \\
\text { Occurrence }\end{array}$ \\
\hline
\end{tabular}

Observation-Based Information

76.1

Asking for or sharing factual, noninferential information. Only communications that could be potentially verified by means of observation are coded in this category.

\section{Suggestion}

Providing or requesting a direction for action. Giving or asking for an opinion of what might be successful or unsuccessful also should be coded in this category.

\section{Conceptual Information}

Communication about a concept; asking for or sharing information about an idea. The message might include a definition of an idea, a rationale for implementing or not implementing an idea, or a speculation about the causes of a problem.

\section{Personal Information}

Communication of a personal experience, thought, opinion, or feeling, which is not intended to facilitate the problem-solving process.

Support

These messages are intended to build a "healthy" social climate. They might focus on tension release/ humor, acceptance of feelings, encouragement, or being friendly.

\section{Specific Feedback}

An evaluation of a specific activity performed by one person. This category includes messages that convey whether or not the person's ideas or suggestions have been used or accepted.

Group Feedback

An evaluation of two or more group members' performance or the entire group's performance. order to reflect the nonsupervisory nature of the roles and relationships in our study. Because of our interest in assessing perceptions of learning, we expanded Cherniss's single category of inform into three categories: (1) conceptual information, (2) personal information, and (3) observation-based information. We also dropped two of Cherniss's categories (i.e., guide, observe) that seemed ill-suited for studying CMC. Two graduate students in psychology independently coded all the messages with respect to the eight content categories listed in Table 1. The average percent agreement for the eight content categories was 83.8 .

At the end of the 5th month of training, each trainee was requested to review all the electronic messages that were either sent to him/her or written by him/her. More specifically, after rereading each message, the trainees were asked to indicate what messages contributed to their expertise in team problem solving. Customized message and answer booklets were mailed to each trainee. The booklets contained only the electronic messages that were sent to the trainee or to the entire group of trainees, or were written by that specific trainee. In the same mailing, participants also received a questionnaire that measured their perceptions of the relative importance of the CMC and FTF training modalities in developing their expertise in team problem solving. Perceptions were assessed with respect to a 7-point Likert-type scale which ranged from 1 (not at all important) to 7 (extremely important). In regard to CMC training, participants were requested to rate their perceptions of three training dimensions: (1) recording self-reflections, (2) communicating with teammates, and (3) communicating with the linchpin expert. All dimensions contained the same nine items. The items reflected the problem-solving steps that had been addressed in training (e.g., defining the problem). The rating of the FTF training used the same nine items with respect to the following training dimensions: (1) initial 3 days of training, (2) follow-up session with linchpin expert, and (3) informal discussions with teammates.

\section{RESULTS}

A total of 134 electronic messages were exchanged among the 5 participants during the 5 months of training. Not unlike FTF groups, some participants contributed a disproportionate number of messages. The two most frequent contributors, both trainees, composed a total of $47 \%$ of the 134 messages. The linchpin expert composed another $18.7 \%$ of the messages. The average length of a message was 7.47 sentences $(S D=6.69)$. A sentence was defined by the composer's use of a period after a series of words. The frequency of occurrence of the different content categories is presented in Table 1. Observationbased information occurred most frequently in messages (76.1\% of messages), and global feedback was found least often ( $9.7 \%$ of messages). On the average, the participants perceived that $54.8 \%$ of the messages enhanced their expertise in team problem solving. However, the percentage of messages perceived as useful varied widely among the participants, with 2 participants perceiving less than $27 \%$ of the messages as being helpful, whereas all of the other 3 perceived more than $68 \%$ of the messages as being helpful.

Logistic regression was used to investigate the relationship between the eight content categories (independent variables) and the perceived extent to which the messages enhanced the participants' expertise in team problem solving. The eight variables, as a group, were significantly related to the participants' perceptions of 
Table 2

Perceived Importance of Computer-Mediated and Face-to-Face Training Modalities in Developing Expertise

\begin{tabular}{llr}
\hline \multicolumn{1}{c}{ Modality } & $M$ & $S D$ \\
\hline Computer-Mediated Training & & \\
$\quad$ Self-reflections & 3.94 & 1.37 \\
Communicating with teammates & 4.47 & .74 \\
$\quad$ Communicating with linchpin expert & 5.47 & .73 \\
Face-to-Face Training & & \\
Initial 3 days with team of trainers & 5.16 & 1.27 \\
Follow-up sessions with linchpin expert & 6.25 & .53 \\
Discussions with team members & 5.89 & .38 \\
\hline
\end{tabular}

Note-Scale ranged from 1 (not at all important) to 7 (extremely important).

the messages $\left[\chi^{2}=39.25, p<.001\right]$. However, individually, only two of the content categories were significantly related to the dependent variable. These two content categories were (1) specific feedback $\left[\chi^{2}=9.57, p=.002\right]$, and (2) conceptual information $\left[\chi^{2}=10.00, p=.002\right]$. None of the six other content categories even approached statistical significance.

Four of the 5 participants responded to items measuring their perceptions of the relative importance of the computer-mediated and FTF training modalities in developing their expertise in team problem solving. The results are presented in Table 2 . All modalities approached or exceeded the mean of the scale (4), indicating that the participants perceived all modalities to be at least moderately important in facilitating their expertise. Nonetheless, the ratings suggest that the participants viewed FTF training as being more valuable than computer-mediated training. Moreover, within both the computer-mediated and FTF areas, training with the linchpin expert was perceived to be the most important type of modality.

\section{DISCUSSION}

The most important finding of the study is that some types of Internet messages were perceived as more important in developing expertise than others. Messages that contained either conceptual information or specific outcome feedback about an individual's actions were significantly related to the perceived utility of the messages. Our results on computer-mediated feedback are consistent with what has been learned about FTF training; specific feedback is more valuable in skill development than global feedback, and this type of feedback is central to developing expertise (Ericsson et al., 1993). In addition, it is notable that over a third of the Internet messages in our study contained specific outcome feedback about an individual's actions. The relationship between conceptual information and perceived usefulness of the message seems consistent with one of the apparent strengths of CMC: the tendency for people to share ideas with one another, unfettered by typical social conventions (Sproull \& Kiesler, 1991).

An interesting avenue for future work is to develop and evaluate an expert system that would provide the trainees with the type of message content, such as specific outcome feedback, needed to develop expertise. Over a long period of time, such an expert system might provide a relatively low-cost and complementary approach to FTF training. Clearly, more research is needed on the relationship between the content of the electronic mail messages and learning. Future research might explore whether there are aspects of providing specific feedback and conceptual information that are more important to learning via electronic mail messages than learning in FTF modalities. An answer to that question would require more fine-grained distinctions than are present in our current coding categories.

In regard to perceived importance of computer-mediated training modalities, two findings emerged. The participants perceived that computer-mediated training was important to the development of their expertise, but did not perceive computer-mediated training to be as important as FTF training. It is possible that the limitations of $\mathrm{CMC}$, such as lack of social cues and an inability to clarify and respond to others' comments immediately (Sproull \& Kiesler, 1991) prevented the Internet messages from being as highly valued as FTF communications.

Of particular note were the sometimes large individual differences among the participants with respect to how much they valued computer-mediated training. The ratings of the computer-mediated training modalities tended to have larger standard deviations than did the ratings of the FTF modalities, and the percentage of messages perceived useful by individual participants ranged from a low 23.5 to a high of 83.3. Moreover, 1 of the original 7 trainees voluntarily chose not to use the Internet part of the training, only reading or composing less than $10 \%$ of the messages. These data suggest that whereas most individuals feel comfortable with FTF training, far fewer may have the same level of comfort with computer-mediated training. More research is needed in order to ascertain if computermediated training can be adapted to these individuals' preferences.

Our results also indicate that the expert may have as important a role to play in computer-mediated training as he/she does in FTF training. Indeed, if learning is to be facilitated, the free sharing of ideas on the Internet does not seem to obviate the need for expertise. Because we used only one training approach with one group of trainees, we do not know whether the linchpin expert approach would produce appreciably better results than other types of training would. What we do know is that the participants, in general, seemed pleased with the training they received.

We were surprised that the participants rated computermediated self-reflections as being the least important training modality, because prior research (e.g., Short \& Rinehart, 1993) has found that self-reflection is related to enhanced expertise. It is possible that the rudimentary electronic mail system used in the study did not make the recording of self-reflections an attractive task. Another possible explanation concerns the content of the training program, team problem solving. It encompasses how 
group members relate to one another with regard to a problem. Thus, in attempting to master a highly social domain, individuals might find communication with colleagues or an expert more helpful than self-reflections.

In summary, the results suggest that the Internet has substantial promise for enhancing traditional training. In addition, we hope that our exploratory case study provides valuable directions for future research, such as systematically relating the content of messages to training outcomes and testing the linchpin expert approach against other approaches to training.

\section{REFERENCES}

Bangert-Drowns, R. L., Kulik, C. C., Kulik, J. A., \& Morgan, M. T (1991). The instructional effect of feedback in test-like events. $R e$ view of Educational Research, 61, 213-238.

BUTLER, D. B., \& WINNE, P. H. (1995). Feedback and self-regulated learning: A theoretical synthesis. Review of Educational Research, 65, 245-282

ChERNIss, C. (1986). Instrument for observing supervisor behavior in educational programs for mentally retarded children. American Journal of Mental Deficiency, 91, 18-21.

Collins, D. (1986). Competency-based field instruction: Bridging the gap between laboratory and field learning. Clinical Supervisor, 4(3), 39-52.
DAVIS, F. B. (1989). Perceived usefulness, perceived ease of use, and user acceptance of information technology. MIS Quarterly, 13, 318-339.

Ericsson, K. A., Krampe, R. T., \& Tesch-Romer, C. (1993). The role of deliberate practice in the acquisition of expert performance. Psychological Review, 3, 363-406.

FullaN, M. G. (1991). The new meaning of educational change. New York: Columbia University, Teachers College Press.

JoHnston, B. (1988). Workforce 2000. Washington, DC: U.S. Government Printing Office.

Kraut, R., Galegher, J., Fish, R., \& Chalfonte, B. (1992). Task requirements and media choice. Human-Computer Interaction, 7 , 375-407.

MOORHEAD, G., \& Griffin, R. W. (1995). Organizational behavior (4th ed.). Boston: Houghton Mifflin.

SHORT, P. M., \& RiNeHART, J. S. (1993). Reflection as a means of developing expertise. Educational Administration Quarterly, 29, 501-521.

Siegel, J., Dubrovsky, V., Kiesler, S., \& McGuire, T. (1986). Group processes in computer-mediated communication. Organizational Behavior \& Human Decision Processes, 37, 157-187.

Sprovll, L., \& Kiesler, S. (1991, September). Computers, networks, and work. Scientific American, 265(3), 116-123.

Stevens, R. J., \& Slavin, R. E. (1995). The cooperative elementary school: Effects on students' achievement, attitudes, and social relations. American Educational Research Journal, 32, 321-351.

WARR, P. (1995). Trainee characteristics and the outcomes of open learning. Personnel Psychology, 48, 347-375.

(Manuscript received November 20, 1995; revision accepted for publication February 8, 1996.) 